\title{
Fungus Gnat Feeding and Mechanical Wounding Inhibit Pythium aphanidermatum Infection of Geranium Seedlings
}

\author{
S. E. Braun, J. P. Sanderson, E. B. Nelson, M. L. Daughtrey, and S. P. Wraight
}

First and second authors: Department of Entomology, and third and fourth authors: Department of Plant Pathology and Plant-Microbe Biology, Cornell University, Ithaca, NY 14853-0901; and fifth author: United States Department of Agriculture-Agricultural Research Service, Robert H. Holley Center for Agriculture \& Health, Ithaca, NY 14853-2901.

Accepted for publication 18 July 2009.

\begin{abstract}
Braun, S. E., Sanderson, J. P., Nelson, E. B., Daughtrey, M. L., and Wraight, S. P. 2009. Fungus gnat feeding and mechanical wounding inhibit Pythium aphanidermatum infection of geranium seedlings. Phytopathology 99:1421-1428.

A series of laboratory tests were conducted to investigate potential effects of fungus gnat (Bradysia impatiens) feeding damage on susceptibility of geranium seedlings (Pelargonium $\times$ hortorum) to infection by the root rot pathogen Pythium aphanidermatum. Effects were compared with those from similar tests in which the seedlings were mechanically wounded by severing the root tip with a scalpel. Assays of geranium seedlings in petri dishes revealed a pronounced negative fungus gnat-Pythium interaction, with exposure to fungus gnat larvae $24 \mathrm{~h}$ prior to inoculation with $P$. aphanidermatum zoospores resulting in up to $47 \%$

had acted independently. Similar results were observed when seedlings were subjected to mechanical wounding $24 \mathrm{~h}$ prior to zoospore inoculation. In contrast, no interaction occurred when seedlings were mechanically wounded immediately prior to inoculation. The degree of plant damage inflicted by the feeding activities of the larval fungus gnats had no significant effect on the combined damage from fungus gnats and Pythium in petri dishes. Ancillary studies showed that Pythium development on V8 agar was not inhibited by the presence of fungus gnatassociated microorganisms, nor were seedlings inoculated with these microbes less susceptible to Pythium infection. The precise mechaism or mechanisms underlying the observed interactions were not elucidated; however, the results strongly suggest that both fungus gnat feeding and mechanical wounding activated systemic defenses that made the seedlings more resistant to Pythium infection.
\end{abstract} fewer seedling deaths than would have been expected if the two agents
Plants are constantly threatened by a number of biotic stresses. Plant response to herbivore or pathogen attack is variable in space and time and depends on the ability of a plant to respond with induced resistance or to tolerate attacking organisms. Abiotic and ontogenetic factors influence plant-antagonist interactions as well. Plants are often attacked by more than one organism at a time, forcing them to mount an integrated system of defense against diverse enemies. The order in which different antagonists associate with a plant affects the type and degree of response $(5,24,35)$.

Plant pathogens vectored by insects can have devastating effects on plants. This association of insects with plant pathogens has been documented for more than a century (39). In commercial greenhouses, insects previously considered nuisances have been implicated in the spread of soilborne pathogens. One key example of such insect pests is a dark-winged fungus gnat of the genus Bradysia (Diptera: Sciaridae) (19). Adult fungus gnats transmit a variety of plant pathogens that produce aerial dispersal stages, including spore-producing fungi such as Fusarium avenaceum (Fr.) Sacc., F. foetens Schroers, O’Donnell, Baayen \& Hooftman, F. oxysporum f. sp. radicis-lycopersici Jarvis \& Shoemaker, Thielaviopsis basicola (Berk. \& Broome) Ferraris, and Verticillium albo-atrum Reinke \& Berthold $(8,9,12,18,23)$.

Wounding by fungus gnats may also influence pathogen infection (19). Leath and Newton (25) found that alfalfa and red clover plants injured by fungus gnat (Bradysia sp.) larvae prior to inoculation with Fusarium spp. died at a much higher rate than uninjured plants. A possible correlation between Bradysia fungus

Corresponding author: S. E. Braun; E-mail address: sea35@ cornell.edu

doi:10.1094/PHYTO-99-12-1421

(c) 2009 The American Phytopathological Society gnat infestations and root rot diseases caused by Pythium has also been observed. Plants infected with Pythium are often also infested with fungus gnat larvae. Both of these organisms are important pests of greenhouse floriculture, and it is generally thought that fungus gnats vector Pythium. However, interactions among fungus gnats, Pythium, and floral crops have not been thoroughly investigated experimentally $(11,21)$. The primary objective of this study was to determine if wounding damage inflicted by fungus gnat larvae affects susceptibility of geranium seedlings (Pelargonium $\times$ hortorum $\mathrm{L}$. H. Bailey) to infection by Pythium aphanidermatum (Edson) Fitzp. Additional objectives included determining whether $P$. aphanidermatum infection is impacted by the microfloral community associated with fungus gnats or by mechanical wounding. Preliminary studies were also conducted to estimate the median lethal concentration $\left(\mathrm{LC}_{50}\right)$ of $P$. aphanidermatum zoospores against geranium seedlings in the bioassay systems to be described. This information was needed to determine an appropriate target zoospore dose for tests involving single-dose inoculations, which were part of the main objectives.

\section{MATERIALS AND METHODS}

Insect rearing. A laboratory colony of Bradysia impatiens (Johannsen) was established with adults collected from a greenhouse on the Cornell University campus. Adults and larvae were routinely reared in plastic containers $(9.8 \mathrm{~cm}$ in diameter by $6.2 \mathrm{~cm}$ in depth; Pioneer Plastics, Dixon, KY) with lids bearing holes $(5.5 \mathrm{~cm}$ in diameter) covered with nylon mesh $(95 \mu \mathrm{m})$ for ventilation. Fifty fungus gnat adults (predominately females) were placed in each container for egg production and provided with $\approx 40 \mathrm{~g}$ of growing medium (Premier Pro-Mix BX, Quakertown, PA) saturated with tap water and $\approx 10 \mathrm{~g}$ (dry weight) of 
ground pinto beans (Goya Foods, Inc., Secaucus, NJ). Colony containers were maintained at $27 \pm 1^{\circ} \mathrm{C}$ with $14 \mathrm{~h}$ of light and $10 \mathrm{~h}$ of darkness. New containers were established daily to provide a constant supply of all life stages. To obtain an evenaged cohort of fourth-instar fungus gnat larvae for use in bioassays, $\approx 200$ adult fungus gnats were collected from colony containers and released into a 45 -by-45-by-45.5-cm cage in the laboratory at ambient temperature $\left(\approx 24^{\circ} \mathrm{C}\right)$ and allowed to oviposit on 90-mm-diameter petri dishes (Becton Dickinson Labware, Franklin Lakes, NJ) that contained saturated cotton covered with a piece of black filter paper spread with a thin layer $(\approx 1.6 \mathrm{~g})$ of ground pinto beans (Phaseolus vulgaris L.). After $24 \mathrm{~h}$, petri dishes were removed from cages and the fungus gnat cultures maintained until the larvae completed development to the fourth instar. Additional water and pinto beans were added to the dishes as needed to provide adequate food and water. Fourthinstar larvae were readily identified on the surface of the filter paper and transferred to bioassay containers using a fine brush.

Plant propagation. Assays were conducted in petri dishes for simplicity and careful observation; other assays were conducted with vermiculite growing medium in plug cells to simulate commercial growing conditions. Geranium seeds (Pelargonium $\times$ hortorum 'Orbit White', Goldsmith Seeds) for petri dish bioassays were surface sterilized in a $0.5 \%$ sodium hypochlorite solution for $3 \mathrm{~min}$, rinsed in sterile distilled water $\left(\mathrm{SDH}_{2} \mathrm{O}\right)$, and germinated individually on top of one disk of filter paper $(42.5 \mathrm{~mm}$ in diameter) saturated with $400 \mu \mathrm{l}$ of $\mathrm{SDH}_{2} \mathrm{O}$ in tight (friction)-lid petri dishes (47 $\mathrm{mm}$ in diameter). The seed were incubated in darkness for 3 days at room temperature. Seedlings were maintained at $27 \pm 1^{\circ} \mathrm{C}$ with $14 \mathrm{~h}$ of light and $10 \mathrm{~h}$ of darkness and watered daily (with $200 \mu \mathrm{l}$ of $\mathrm{SDH}_{2} \mathrm{O}$ ) until they were used in bioassays. The seedlings were oriented horizontally in the petri dishes (lying on the filter paper).

Seed used in vermiculite/plug tray bioassays were also surface sterilized (as described above) and germinated on top of two disks of filter paper ( $90 \mathrm{~mm}$ in diameter) saturated with $2.2 \mathrm{ml}$ of $\mathrm{SDH}_{2} \mathrm{O}$ in petri dishes (90 $\mathrm{mm}$ in diameter) sealed with Parafilm. The seeds were incubated in darkness at room temperature until germination (3 to 4 days) and then planted in water-saturated, coarse vermiculite within individual plug cells $(\approx 26-\mathrm{ml}$ volume $)$ that were cut from 128-well plug trays (Dillen Products/Myers Industries Inc., Middlefield, OH). Plug cells were placed in 55-ml plastic vials and $\mathrm{SDH}_{2} \mathrm{O}$ was added at rates described below for each experiment. Vermiculite was selected as the potting medium because Pythium infection was not consistent in a variety of peatbased plug mixes commonly used by growers.

At the initiation of bioassays, seedlings were, in most cases, 7 to 8 days old (days post seed hydration), $\approx 4 \mathrm{~cm}$ in length, and consisted of short hypocotyls terminating in two cotyledons and an unbranched root with dense root hairs.

Pathogen maintenance. Pythium aphanidermatum (strain Pa58) cultures were grown in 60-mm-diameter petri dishes on V8 juice agar (composed of $100 \mathrm{ml}$ of V8 juice, $400 \mathrm{ml}$ of $\mathrm{H}_{2} \mathrm{O}, 1.5 \mathrm{~g}$ of $\mathrm{CaCO}_{3}$, and $10 \mathrm{~g}$ of Bacto Agar) and maintained in the dark at $27 \pm 1^{\circ} \mathrm{C}$. One-week-old cultures of $P$. aphanidermatum were used in all experiments. Every 2 weeks, the pathogen was reisolated from 11-day-old geranium seedlings that had been inoculated 3 days earlier by placing a 6-mm-diameter agar disk (from 1-week-old culture) of $P$. aphanidermatum on the root tip. Each infected seedling was placed in a 90-mm-diameter petri dish and covered with $2 \%$ molten water agar supplemented with the antibiotics rifampicin, penicillin $\mathrm{G}$, and kanamycin (at 1.0, 1.0, and $2.5 \mathrm{ml} /$ liter of $\mathrm{SDH}_{2} \mathrm{O}$, respectively) (WARP). After the agar solidified, plates were incubated as described above. P. aphanidermatum hyphae that grew rapidly through the agar were excised from the surface of the medium and transferred to a fresh WARP plate. In the following descriptions of methods, the term "replicate assays" refers to assays conducted on different days, using freshly prepared $P$. aphanidermatum inocula.

Inoculum preparation. Zoospore suspensions were produced by placing one 20 -mm-diameter agar disk from a 1 -week-old $P$. aphanidermatum culture into a $60-\mathrm{mm}$ petri dish containing $10 \mathrm{ml}$ of $\mathrm{SDH}_{2} \mathrm{O}$. Zoospore culture plates were started at $1700 \mathrm{~h}$ on the day prior to the start of an assay. The dish was sealed with parafilm and incubated as described above. The sterile water was replaced with $10 \mathrm{ml}$ of fresh $\mathrm{SDH}_{2} \mathrm{O}$ the following morning and zoospores were collected $6 \mathrm{~h}$ later for use in the assay.

Approximate desired concentrations of zoospores for bioassays were obtained by preparing serial dilutions in $\mathrm{SDH}_{2} \mathrm{O}$. Concentrations of zoospores in stock suspensions and initial dilutions in a series were estimated by standard hemacytometer counting. Four independent samples from each dilution were counted. Numbers of zoospores in dilute suspensions were determined by spreading a 200- $\mu$ l sample onto V8 agar in a 90-mm-diameter petri dish (three replicate plates per dilution). CFU were counted on each plate after $24 \mathrm{~h}$ of incubation as described above.

$\boldsymbol{P}$. aphanidermatum $\mathbf{L C}_{50}$ estimations. Four replicate multidose petri dish bioassays were conducted to determine the $\mathrm{LC}_{50}$ of $P$. aphanidermatum zoospores. Four zoospore dose levels and a sterile water control were used in each assay. For the first three assays, the zoospore stock suspension was serially diluted $10 \times$, $10 \times, 3 \times$, and $3 \times$. In the fourth assay, the stock suspension was serially diluted $10 \times, 5 \times, 3 \times$, and $3 \times$. Individual seedlings in tightlid petri dishes ( $47 \mathrm{~mm}$ in diameter) were inoculated by pipetting $400 \mu \mathrm{l}$ of one of the four zoospore dilutions onto the filter paper adjacent to the root tip of the plant. Controls were inoculated with

TABLE 1. Median lethal concentration $\left(\mathrm{LC}_{50}\right)$ estimates from replicated four-dose bioassays of Pythium aphanidermatum against geranium seedlings in petri dishes and plug trays

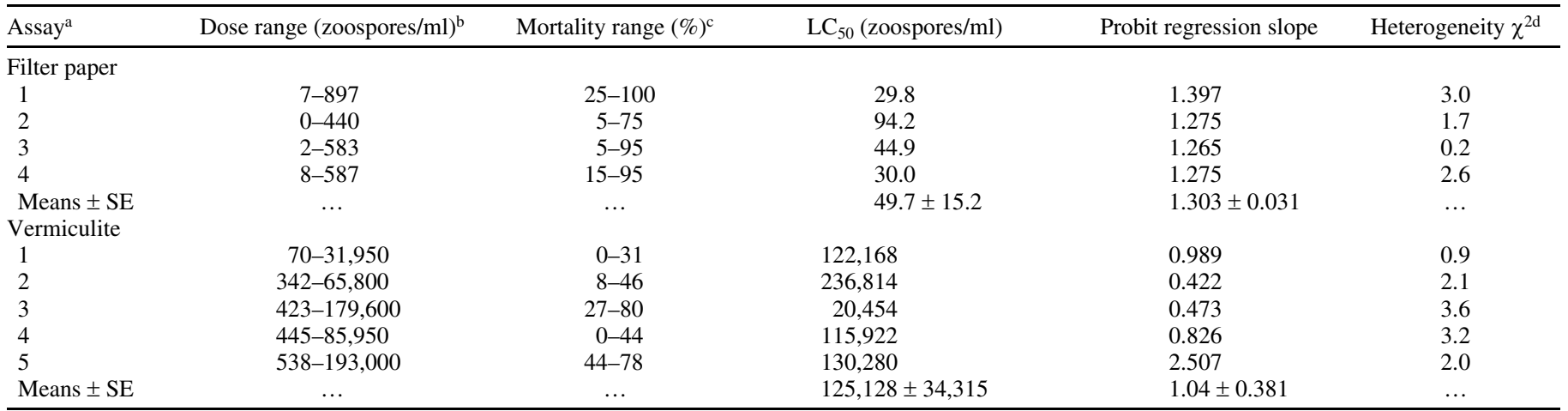

\footnotetext{
a Seedling rooted either on moist filter paper in petri dishes (Filter paper) or in vermiculite in plug trays (Vermiculite); $\mathrm{SE}=$ standard error.

${ }^{\mathrm{b}}$ Range of doses (expressed as viable zoospores per milliliter) applied in each bioassay.

${ }^{\mathrm{c}}$ Range of geranium seedling mortality recorded across doses.

${ }^{\mathrm{d}}$ Heterogeneity $\chi^{2}$ (with 2 degrees of freedom) indicating goodness-of-fit of the data to the probit-log dose linear regression model (10).
} 
$400 \mu \mathrm{l}$ of $\mathrm{SDH}_{2} \mathrm{O}$. In all, 100 seedlings were inoculated per assay (20 per zoospore dose and control). Mortality of seedlings was recorded 7 days postinoculation.

Five replicate multidose bioassays were conducted to determine the $\mathrm{LC}_{50}$ of $P$. aphanidermatum zoospores against geranium seedlings rooted in vermiculite. For all assays, three $5 \times$ dilutions with $\mathrm{SDH}_{2} \mathrm{O}$ were made to the zoospore stock suspension. Individual 8-day-old geranium seedlings in vermiculite-filled plug cells were inoculated by pipetting $2 \mathrm{ml}$ of either one of the four zoospore suspensions or sterile water near the crown of the plant. In all, 65 to 90 seedlings were used per assay (13 to 18 per zoospore dose and control). The seedlings were maintained at $27 \pm 1^{\circ} \mathrm{C}$ with $14 \mathrm{~h}$ of light and $10 \mathrm{~h}$ of darkness and watered daily with $1 \mathrm{ml}$ of sterile water. Mortality of seedlings was recorded 7 days postinoculation.

Effect of fungus gnat wounding on Pythium infection. In total, 24 assays were conducted to determine the effects of plant wounding on subsequent $P$. aphanidermatum infection of geranium seedlings growing on water-saturated filter paper in petri dishes. Twenty-one of these assays included treatments designed to determine whether the time of seedling exposure to fungus gnat larvae influenced infection. Each assay was designed as a two-by-two factorial with all combinations of fungus gnat larval presence or absence and $P$. aphanidermatum inoculum presence or absence as the four treatments (see statistical analysis section). Geranium seed were germinated as described above. When the seedlings were 7 days old, fourth-instar fungus gnat larvae were placed in half of the dishes (three larvae/dish) and allowed to feed on the seedlings. The plants were exposed to the larvae for $24 \mathrm{~h}$ at $27 \pm 1^{\circ} \mathrm{C}$ with $14 \mathrm{~h}$ of light and $10 \mathrm{~h}$ of darkness, after which time the larvae were removed. Preliminary experiments demonstrated that fungus gnats reliably caused plant damage that was visible by $24 \mathrm{~h}$. Fungus gnat damage was assessed on each plant according to the following scale: $1=$ no visible damage or damaged root hairs or minor abrasions; $2=$ clearly evident feeding damage scarring the root, hypocotyl, or cotyledon surface; and 3 = severed root, tunneling in stem or root column, hole in cotyledon. Dishes to be treated with $P$. aphanidermatum were then inoculated by pipetting $400 \mu$ of a $P$. aphanidermatum zoospore suspension (150x dilution of stock suspension) onto the filter paper near the root tip of the plant. Doses (CFU) applied in each of the replicate assays were quantified using the above-described CFU plating method. Each treatment included 20 to 25 seedlings. Mortality of seedlings was recorded 7 days postinoculation.

Four laboratory bioassays were conducted to determine the effects of exposure to fungus gnat larvae on subsequent $P$. aphanidermatum infection of geranium seedlings rooted in vermiculite-filled plug cells contained in plastic vials (see plant propagation section). Each assay was designed as a two-by-two factorial with all combinations of fungus gnat larval presence or absence and $P$. aphanidermatum inoculum presence or absence as the four treatments. Fourth-instar fungus gnat larvae were then placed in half of the cells (three larvae/cell) and allowed to feed on the 7-day-old seedlings. At $24 \mathrm{~h}$ after introduction of the larvae, the dishes were inoculated with $P$. aphanidermatum by

TABLE 2. Percent mortality of geranium seedlings in 28 damaged-plant assays

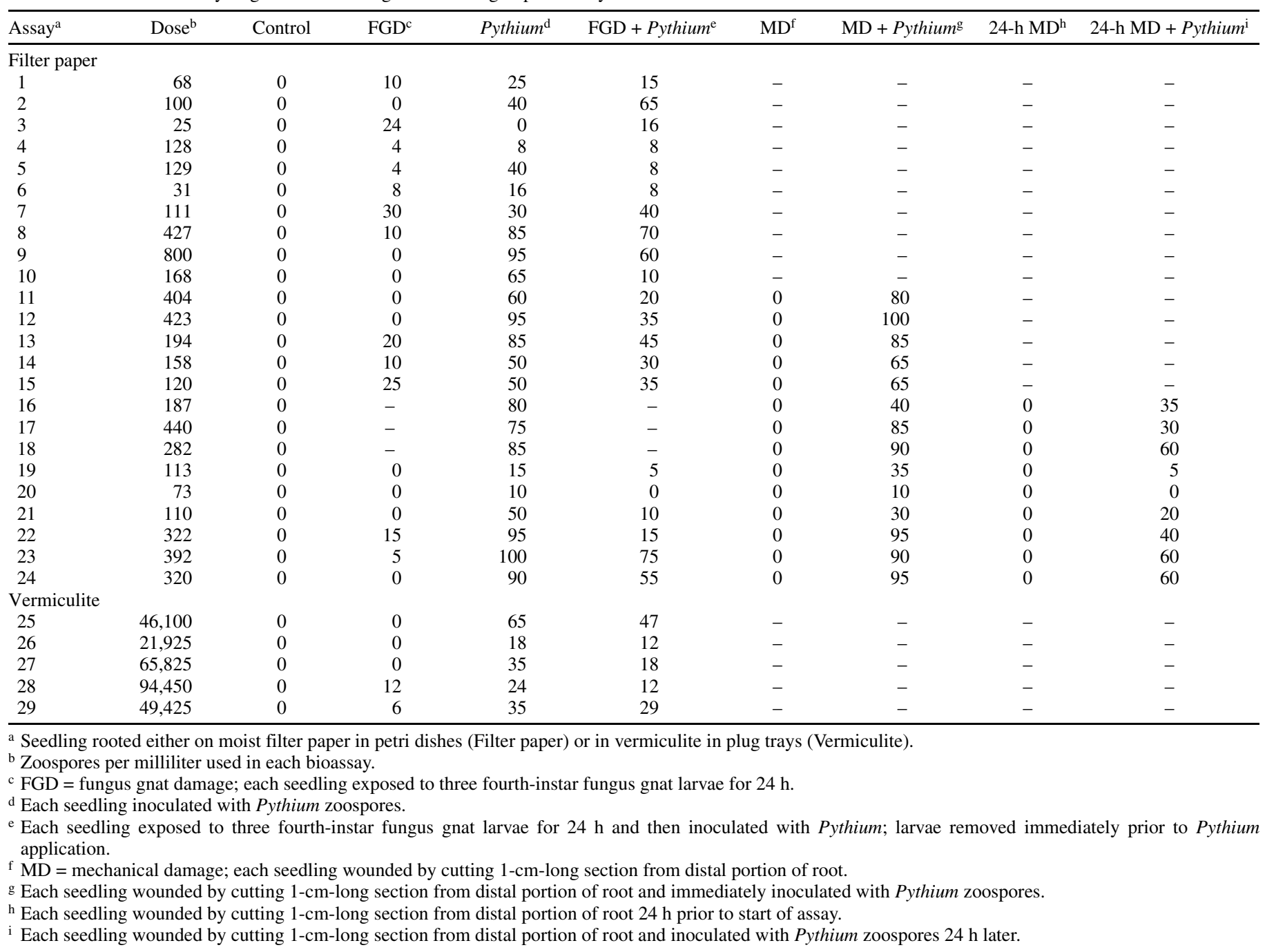


pipetting $2 \mathrm{ml}$ of a stock zoospore suspension onto the vermiculite adjacent to the crown of the plant. Doses applied in each of the four replicate assays were quantified by hemacytometer. In all, 68 seedlings were used per assay (17 per treatment). The seedlings were maintained at $27 \pm 1^{\circ} \mathrm{C}$ with $14 \mathrm{~h}$ of light and $10 \mathrm{~h}$ of darkness. At initiation of the assays, $\mathrm{SDH}_{2} \mathrm{O}$ was added to each vial to a level $1 \mathrm{~cm}$ above the bottom of the plug cell, and water was subsequently added once daily to restore this level. Mortality of seedlings was recorded 7 days postinoculation.

Effect of mechanical wounding on Pythium infection. Of the above-mentioned 24 petri dish assays, 14 included treatments to determine the effects of mechanical wounding of plants on subsequent $P$. aphanidermatum infection of geranium seedlings. Each assay was designed as a two-by-two factorial with all combinations of mechanical wounding presence or absence and $P$. aphanidermatum presence or absence as the four treatments. Mechanical wounding was achieved by cutting a 1-cm-long section from the distal portion of the root of each seedling using a sterilized scalpel. In each of the 14 assays, $P$. aphanidermatum zoospores were applied to 8-day-old seedlings immediately after wounding. In 9 of the 14 assays, zoospores were applied to seedlings that had been wounded $24 \mathrm{~h}$ previously (when 7 days old). Twenty seedlings were used per treatment. Mortality of seedlings was assessed 7 days postinoculation.
Effect of fungus gnat-associated microbes on Pythium infection. Four bioassays were conducted to determine the possible effects of the fungus gnat larval microbial community on $P$. aphanidermatum infection of geranium seedlings. Fungus gnat rinsate was generated by placing three fourth-instar fungus gnat larvae in a sterile $2-\mathrm{ml}$ centrifuge tube with $10 \mu \mathrm{l}$ of sterile water. The tube was then vortexed for $30 \mathrm{~s}$ to remove microorganisms from the fungus gnats' bodies. Eighty 7-day-old seedlings per assay were treated by applying $10 \mu \mathrm{l}$ of fungus gnat rinsate via pipette to either the crown or the root tip of a seedling (20 seedlings/treatment). In corresponding control treatments, $\mathrm{SDH}_{2} \mathrm{O}$ was applied instead of rinsate. Three replicate 200- $\mu$ l samples of each rinsate (diluted 2,000×) were also pipetted onto V8 agar plates for CFU counts. One day after application of the rinsate treatments, the seedlings were inoculated with $P$. aphanidermatum zoospores and monitored for mortality as described above.

An additional assay was conducted in vitro to assess possible antagonistic effects of the fungus gnat-associated microbes on $P$. aphanidermatum infection. One 6-mm-diameter agar disk from a 1-week-old culture of $P$. aphanidermatum was placed on the surface of V8 medium in the center of each dish. In one treatment, three $10-\mu l$ droplets of fungus gnat rinsate were applied individually along the circumference of the dish equidistant from the $P$. aphanidermatum plug. In the second treatment, three $10-\mu \mathrm{l}$

TABLE 3. Effects of inoculation with Pythium aphanidermatum and exposure to fungus gnat larvae on mortality ( \pm standard error) of geranium seedlings in petri dish bioassays

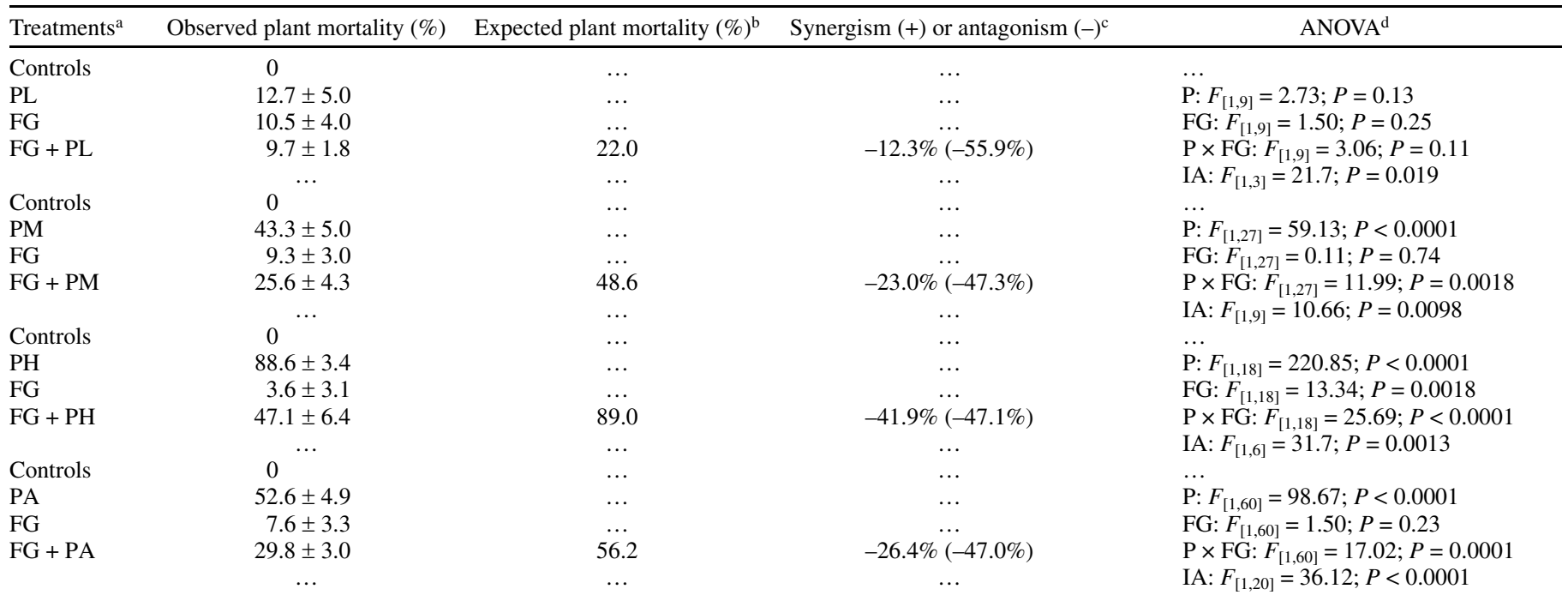

${ }^{a} \mathrm{PL}=$ low dose of Pythium, $n=4$ assays, 25 to 73 zoospores $/ \mathrm{ml} ; \mathrm{FG}=$ fungus gnats, each seedling exposed to three fourth-instar fungus gnat larvae for 24 h; PM $=$ medium dose of Pythium: $n=10$ assays, 100 to 194 zoospores $/ \mathrm{ml}$; PH $=$ high dose of Pythium: $n=7$ assays, 320 to 800 zoospores $/ \mathrm{ml} ;$ PA = all doses; FG + Pythium dose $=$ seedlings exposed to fungus gnat larvae for $24 \mathrm{~h}$ and then inoculated with Pythium; larvae removed immediately prior to Pythium application.

${ }^{\mathrm{b}}$ Control predicted if the agents exhibit independent action; value calculated using the formula for combination of independent probabilities (34).

${ }^{c}$ Antagonism calculated as the difference between observed and expected percent plant mortality. Numbers in parentheses indicate the proportional differences between the observed and expected percent plant mortality.

${ }^{\mathrm{d}}$ Factorial analysis of variance (ANOVA) testing main effects and interaction; one-way ANOVA testing hypothesis of independent action (IA).

TABLE 4. Effects of inoculation with Pythium aphanidermatum and exposure to fungus gnat larvae on mortality ( \pm standard error) of geranium seedlings rooted in vermiculite

\begin{tabular}{lcccc}
\hline Treatments & Observed plant mortality $(\%)$ & ${\text { Expected plant mortality }(\%)^{\mathrm{a}}}$ & ${\text { Synergism }(+) \text { or antagonism }(-)^{\mathrm{b}}}^{\text {ANOVA }^{\mathrm{c}}}$ \\
\hline Controls & 0 & $\ldots$ & $\ldots$ & $\ldots$ \\
Pythium sp. $(\mathrm{P})^{\mathrm{d}}$ & $35.4 \pm 4.8$ & $\ldots$ & $\ldots$ & $\mathrm{P}: F_{[1,12]}=50.8, P<0.0001$ \\
Fungus gnats (FG) & $3.6 \pm 4.6$ & $\ldots$ & $\ldots$ & FG: $F_{[1,12]}=0.26, P=0.62$ \\
P + FG & $23.6 \pm 3.3$ & 37.7 & $-14.1 \%(-37.4 \%)$ & P $\times$ FG: $F_{[1,12]}=3.40, P=0.09$ \\
& $\ldots$ & $\ldots$ & $\ldots$ & IA: $F_{[1,4]}=27.4, P=0.006$ \\
\hline
\end{tabular}

${ }^{a}$ Control predicted if the agents exhibit independent action; value calculated using the formula for combination of independent probabilities (34).

${ }^{b}$ Antagonism calculated as the difference between observed and expected percent plant mortality. Number in parentheses indicates the proportional difference between the observed and expected percent plant mortality.

${ }^{\mathrm{c}}$ Factorial analysis of variance (ANOVA) testing main effects and interaction; one-way ANOVA testing hypothesis of independent action (IA).

d Test comprising $n=5$ assays, 2.2 to $9.4 \times 10^{4}$ zoospores $/ \mathrm{ml}$. 
droplets of rinsate were applied individually to 3-day-old geranium plants situated along the circumference of a $90-\mathrm{mm}$ plate equidistant from the $P$. aphanidermatum plug. Plates were maintained at $27 \pm 1^{\circ} \mathrm{C}$ with $14 \mathrm{~h}$ of light and $10 \mathrm{~h}$ of darkness, and growth of the Pythium sp. was examined 3 days postinoculation. Twelve replicates of each treatment were used. In three replicates, 200- $\mu$ l samples of the fungus gnat rinsate (diluted $8,000 \times)$ were also pipetted onto individual V8 agar plates (90-mm-diameter petri dish) for CFU counts.

Statistical analyses. $\mathrm{LC}_{50} \mathrm{~s}$ of $P$. aphanidermatum zoospores were estimated by probit analysis using the personal computer program PoloPlus (26). All other statistical tests were conducted using the JMP software version 7.0 (36) using analysis of variance (ANOVA) and significance levels of $\alpha=0.05$. All percent mortality data were arcsine transformed prior to parametric ANOVA (37) and aligned-rank transformed for the alternative nonparametric test $(27,33)$. It was not possible to exactly replicate the zoospore dose across assays. Therefore, in order to assess the effect of $P$. aphanidermatum dose on infection of geranium seedlings, it was necessary to combine doses into categories. Three categories were defined: $<100$ zoospores $/ \mathrm{ml}$, 100 to 299 zoospores/ml, or $\geq 300$ zoospores $/ \mathrm{ml}$. Assay was included as a factor (experimental block) in all analyses but interactions with assay were not examined due to restriction error (37). In addition, because assay was confounded with dose, it was not possible to test dose-treatment interactions.

Of the 24 petri dish bioassays, 14 comprised subexperiments investigating effects of exposure to both fungus gnats and mechanical damage on mortality of Pythium-inoculated geranium seedlings. To simplify the interaction analysis and presentation of results, we conducted separate two-by-two factorial analyses of these factors even though independent sets of controls and Pythium-only treatments were not conducted for each subexperiment. Though this approach enables a straightforward presentation of results, caution is called for with any sacrifice of independence. We do not consider this a significant problem in this case, because (i) no control mortality was observed in any of the bioassays, indicating no variance associated with the estimate of $0 \%$ control mortality, and (ii) trends in the data were consistent across a large number of independently replicated assays, translating in many cases to high levels of significance of the tested interactions (especially the fungus gnat-Pythium interactions) $(P$ values $\leq 0.001)$. The lack of control mortality does, however, create a problem with respect to unequal variance across treat- ments. As a consequence, we corroborated the ANOVA results using the nonparametric aligned rank test recommended for factorial designs with interaction $(27,33)$. Results in all cases were similar to the standard ANOVA (often producing increased levels of significance), and we opted to present just the ANOVA results. In addition, we employed one-way ANOVAs to test for independence of the Pythium and fungus gnat (or Pythium and mechanical damage) mortality factors. Mortality predicted by independent action was calculated using the formula for combination of independent probabilities (34), and this expected mortality was compared directly via ANOVA with the observed mortality caused by the agents acting in combination. This comparison excludes the problematic (zero-variance) control treatments from the analysis and, because control mortality was zero, corrections for control mortality were also unnecessary.

The same problem with independence exists with the tests examining effects of variable fungus gnat damage (separate control and Pythium-only treatments were not conducted for each damage level). In this case, there were fewer replicates and smaller sample sizes, and we opted not to conduct the factorial analysis. Instead, the fungus gnat + Pythium treatments were analyzed by one-way ANOVA (percent mortality data arcsine transformed and weighted by sample size) to determine whether there was a significant effect of fungus gnat damage level on mortality of Pythium-inoculated seedlings.

\section{RESULTS}

Establishment of $\boldsymbol{P}$. aphanidermatum $\mathbf{L C}_{50}$ values. The mean $\mathrm{LC}_{50} \pm$ standard error (SE) determined from four replicate bioassays in petri dishes equaled $49.7 \pm 15.2$ zoospores $/ \mathrm{ml}$, with a probit regression slope \pm SE equal to $1.303 \pm 0.031$. The concentrations of viable zoospores per milliliter used in the four assays was 0 to 897 and produced a maximum of $100 \%$ mortality (Table 1). All seedlings remained healthy in the control treatments for the duration of the experiment. Signs of disease in Pythiuminfected plants included watersoaking that made the tissue appear darker green in color and hyphal growth on the surface of the seedling roots and hypocotyl within 7 days after inoculation.

The mean $\mathrm{LC}_{50} \pm \mathrm{SE}$ determined from five replicate bioassays with seedlings rooted in vermiculite equaled $12.5 \times 10^{4} \pm 3.4 \times$ $10^{4}$ zoospores $/ \mathrm{ml}$; mean probit regression slope \pm SE was $1.04 \pm$ 0.381 . The concentrations of viable zoospores per milliliter used in the five assays was 70 to 193,000 and produced a maximum of

TABLE 5. Effects of fungus gnat (FG) damage level on percent mortality ( \pm standard error) of geranium seedlings exposed to Pythium aphanidermatum

\begin{tabular}{|c|c|c|c|c|}
\hline \multirow[b]{2}{*}{ Treatment $^{\mathrm{a}}$} & \multicolumn{3}{|c|}{ FG damage level ${ }^{\mathrm{b}}$} & \multirow[b]{2}{*}{ Analysis of variance } \\
\hline & 1 & 2 & 3 & \\
\hline \multicolumn{5}{|l|}{ Low dose } \\
\hline FG & $3.8 \pm 3.6$ & $3.1 \pm 2.7$ & $25.0 \pm 5.5$ & $F_{2,6}=4.2, P=0.071$ \\
\hline $\mathrm{FG}+\mathrm{P}$ & $8.7 \pm 5.5$ & $14.3 \pm 5.4$ & $8.7 \pm 0.6$ & $F_{2,6}^{2,0}=0.5, P=0.62$ \\
\hline Adjusted FG + P & $7.7 \pm 4.9$ & $12.5 \pm 4.8$ & 0 & $F_{2,6}=5.3, P=0.047$ \\
\hline \multicolumn{5}{|l|}{ Medium dose } \\
\hline $\mathrm{FG}$ & $4.8 \pm 4.1$ & $2.9 \pm 4.2$ & $17.5 \pm 1.8$ & $F_{2,18}=2.3, P=0.13$ \\
\hline $\mathrm{FG}+\mathrm{P}$ & $13.6 \pm 4.1$ & $15.7 \pm 5.4$ & $37.6 \pm 2.8$ & $F_{2,18}=7.5, P=0.004$ \\
\hline Adjusted FG + P & $11.7 \pm 4.3$ & $14.5 \pm 5.1$ & $26.8 \pm 2.6$ & $F_{2,18}=1.9, P=0.18$ \\
\hline \multicolumn{5}{|l|}{ High dose } \\
\hline FG & 0 & 0 & $10.6 \pm 2.3$ & $F_{2,12}=11.7, P=0.002$ \\
\hline $\mathrm{FG}+\mathrm{P}$ & $39.6 \pm 6.3$ & $44.4 \pm 6.6$ & $51.1 \pm 5.1$ & $F_{2,12}=0.9, P=0.44$ \\
\hline Adjusted FG + P & $39.6 \pm 6.3$ & $44.4 \pm 6.6$ & $46.7 \pm 5.1$ & $F_{2,12}=0.43, P=0.66$ \\
\hline \multicolumn{5}{|l|}{ All doses } \\
\hline FG & $2.9 \pm 2.1$ & $2.1 \pm 1.3$ & $17.0 \pm 3.1$ & $F_{2,51}=13.5, P<0.0001$ \\
\hline $\mathrm{FG}+\mathrm{P}$ & $22.5 \pm 4.9$ & $23.2 \pm 6.0$ & $35.0 \pm 5.8$ & $F_{2,51}=1.5, P=0.24$ \\
\hline Adjusted FG + P & $21.5 \pm 4.9$ & $22.3 \pm 6.1$ & $26.6 \pm 6.1$ & $F_{2,51}=0.1, P=0.87$ \\
\hline
\end{tabular}

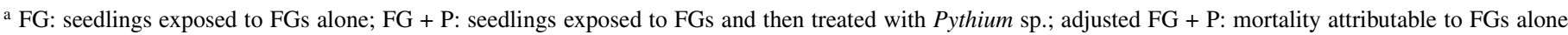
deducted from mortality in the FG + P treatments using Abbott's formula (1). Low dose $=25$ to 73 zoospores/ml, 4 bioassays; Medium dose $=100$ to 194 zoospores/ml, 10 bioassays; High dose $=320$ to 800 zoospores $/ \mathrm{ml}, 7$ bioassays; All doses $=21$ bioassays.

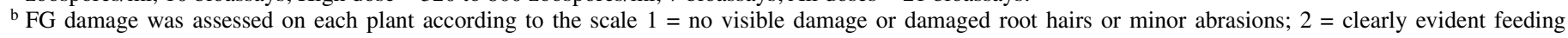
damage scarring the root, hypocotyl, or cotyledon surface; and $3=$ severed root, tunneling in stem or root column, hole in cotyledon. 
$80 \%$ mortality (Table 1$)$. Control treatments $\left(\mathrm{SDH}_{2} \mathrm{O}\right)$ had minimal effect in most cases, with all seedlings in three assays remaining apparently healthy until the assays were terminated. Significant levels of control mortality were recorded in two assays (11 and 22\%); however, none of the affected seedlings showed signs of Pythium infection, and no Pythium sp. was re-isolated from the dead seedlings.

Interaction studies. Results from the 28 assays investigating effects of plant wounding on Pythium infection are presented in Table 2. Assays 1 to 24 were conducted with geranium seedlings on wet filter paper in petri dishes, while assays 25 to 28 were conducted with seedlings rooted in vermiculite in plug cells. No seedling mortality was observed in any of the control treatments across assays and, therefore, all mortality in the fungus gnat-alone and Pythium-alone treatments was attributable to treatment effects (fungus gnat damage or Pythium infection). Interactions were apparent between the main effects of exposure to fungus gnat larvae and inoculation with Pythium as well as between mechanical damage and Pythium inoculation. Evaluation of the significance of these interactions was examined via factorial ANOVA.

Effects of fungus gnat wounding on Pythium infection. Exposure to fungus gnat larvae alone did not cause any significant plant mortality, whereas Pythium alone was highly virulent when zoospores were applied at the intermediate and high doses (Table 3 ). There was, however, an overall significant interaction between the fungus gnat and Pythium treatments. The exposure of seedlings to fungus gnats $24 \mathrm{~h}$ prior to Pythium inoculation resulted in up to $47 \%$ fewer seedling deaths and seedling mortality up to 42 percentage points lower than would have occurred had the two agents operated independently (Table 3 ).

Similar trends were observed with seedlings rooted in vermiculite (Table 4). A negative interaction between the fungus gnat and

TABLE 6. Effects of mechanical wounding and Pythium aphanidermatum dose on geranium seedling mortality ( \pm standard error)

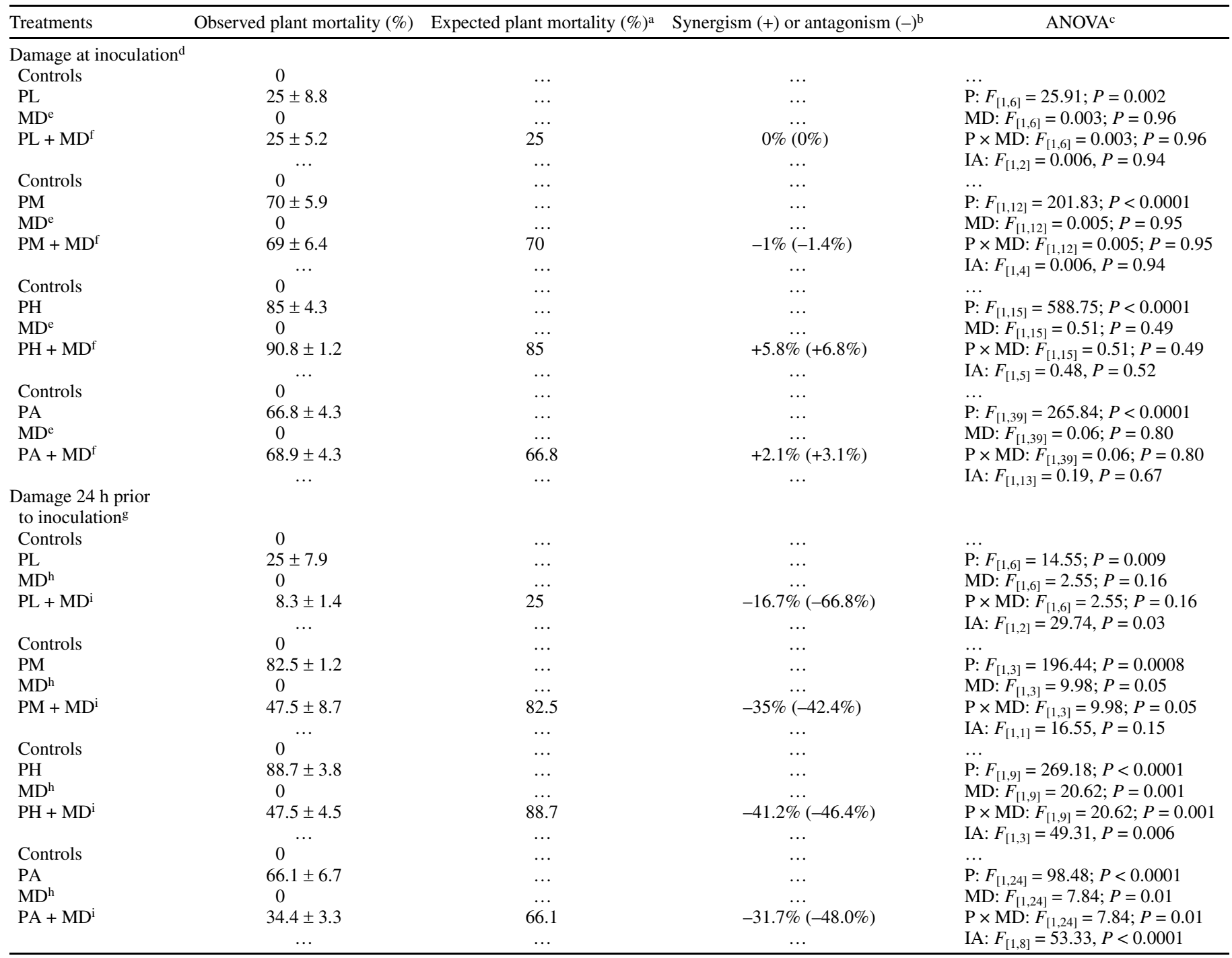

${ }^{a}$ Control predicted if the agents exhibit independent action; value calculated using the formula for combination of independent probabilities (34).

${ }^{\mathrm{b}}$ Synergism and antagonism calculated as the difference between observed and expected percent plant mortality. Numbers in parentheses indicate the proportional differences between the observed and expected percent plant mortality.

${ }^{c}$ Factorial analysis of variance (ANOVA) testing main effects and interaction; one-way ANOVA testing hypothesis of independent action (IA).

d Mechanical damage (MD) at time of Pythium inoculation. PL $=$ low dose: $n=3$ assays, 73 to 113 zoospores $/ \mathrm{ml} ; \mathrm{PM}=$ medium dose: $n=5$ assays, 120 to 282 zoospores $/ \mathrm{ml} ; \mathrm{PH}=$ high dose: $n=6$ assays, 320 to 440 zoospores $/ \mathrm{ml} ; \mathrm{PA}=$ all doses.

${ }^{\mathrm{e}}$ Each seedling wounded by cutting 1-cm-long section from distal portion of root.

${ }^{\mathrm{f}}$ Each seedling wounded by cutting 1-cm-long section from distal portion of root and immediately inoculated with Pythium zoospores.

g MD 24 h prior to Pythium inoculation. PL = low dose: $n=3$ assays, 73 to 113 zoospores $/ \mathrm{ml} ; \mathrm{PM}=$ medium dose: $n=2$ assays, 187 to 282 zoospores $/ \mathrm{ml} ; \mathrm{PH}=$ high dose: $n=4$ assays, 320 to 440 zoospores $/ \mathrm{ml} ; \mathrm{PA}=$ all doses.

${ }^{\mathrm{h}}$ Each seedling wounded by cutting 1 -cm-long section from distal portion of root $24 \mathrm{~h}$ prior to start of assay.

${ }^{\mathrm{i}}$ Each seedling wounded by cutting 1-cm-long section from distal portion of root and inoculated with Pythium zoospores $24 \mathrm{~h}$ later. 
Pythium treatments was apparent, with $37 \%$ fewer seedling deaths and mortality 14 percentage points lower than predicted by independent action.

There was little evidence that the degree of plant damage inflicted by the feeding activities of the larval fungus gnats had any significant effect on the above-described fungus gnatPythium interaction (Table 5). At the medium zoospore doses, seedling mortality increased with increasing damage (from 14 to $38 \%, P=0.004)$; however, this trend was apparent also in the absence of Pythium, and significance was lost $(P$ increased to 0.18 ) when mortality attributable to fungus gnats alone was deducted from mortality in the fungus gnat + Pythium treatments using Abbott's formula (1). In the cases of the low and high doses and when all doses were combined, there were no differences in seedling mortality over the three damage levels (Table 5).

Effects of mechanical wounding on Pythium infection. Mechanical wounding alone did not have a significant effect on plant mortality, whereas Pythium sp. alone had a highly significant effect on plant mortality at all doses (Table 6). There was no significant interaction between mechanical wounding and Pythium treatments (Table 6).

In contrast, mechanical wounding of seedlings $24 \mathrm{~h}$ prior to Pythium inoculation significantly reduced subsequent Pythiuminduced mortality at the high dose but not at the intermediate or low doses, and a significant interaction was detected between mechanical wounding and Pythium (Table 6). The exposure of seedlings to mechanical wounding $24 \mathrm{~h}$ prior to Pythium inoculation resulted in up to $46 \%$ fewer seedling deaths and seedling mortality up to 41 percentage points lower than predicted by independent action (Table 6 ).

Effect of fungus gnat microbes on Pythium infection. Treating seedlings with microbes washed from fungus gnats had no significant effect on mortality due to Pythium infection $\left(F_{[3,9]}=\right.$ $1.1, P=0.40)$. Percent mortality of seedlings in the rinsatecrown, sterile water-crown, rinsate-root tip, and sterile waterroot tip treatments was $46.2 \pm 3.1,51.2 \pm 4.4,52.5 \pm 3.2$, and $56.2 \pm 2.6$, respectively. The concentrations of zoospores used in the four assays was 180 to 412 zoospores $/ \mathrm{ml}$. The fungus gnat rinsates contained an average of $4.2 \times 10^{5}$ bacteria $/ \mathrm{ml}$.

In the presence of fungus gnat rinsates on V8 agar plants, no mycelial inhibition was observed. Furthermore, all of the plants treated with rinsates showed symptoms of $P$. aphanidermatum infection within 2 days. The fungus gnat rinsates contained an average of $1.45 \times 10^{5} \mathrm{bacteria} / \mathrm{ml}$.

\section{DISCUSSION}

The primary goal of this study was to determine if wounding damage from fungus gnat larvae affects the susceptibility of geranium seedlings to infection by $P$. aphanidermatum. The finding that fungus gnat larval feeding reduces infection by $P$. aphanidermatum presents a new and unexpected picture with respect to the role of fungus gnats in the development of plant disease. For example, some previous studies with Bradysia spp. have shown that feeding may promote plant infection by pathogenic fungi $(15,25)$, whereas other studies (12) have demonstrated no enhanced infection from fungus gnat feeding (22). Our results reveal a relationship between fungus gnat feeding and induced resistance to pathogens that has not previously been demonstrated (19).

Fungus gnat larvae have been shown to induce plant defense responses: the jasmonate pathway $(16,20)$ plays a critical role in protecting Arabidopsis thaliana from attack by these insects (29). It is unclear, though, which traits activated by the jasmonate pathway are responsible for increased resistance and whether cross-talk may exist among multiple plant-defense-signaling pathways $(20,29)$. Furthermore, it is possible that defense responses induced by insect feeding may influence subsequent biotic attackers (5). For example, tomato plants previously infested with silverleaf whitefly, Bemisia argentifolii, are more resistant to the fungal pathogen Erysiphe cichoracearum than are control plants (28). Because jasmonic acid mediates pathways that confer partial tolerance to necrotrophic pathogens such as Pythium (13,31), it is possible that fungus gnat feeding inhibited Pythium infection via the jasmonate response in the current study.

Increasing fungus gnat feeding damage did not increase the level of Pythium infection. If increased damage were directly correlated with the level of induced resistance, the expected result would be decreasing mortality with increasing damage. This was not the case (Table 5). These findings agree with recent studies indicating that plants can initiate rapid defense responses within minutes of an insect contacting a plant, and even the nonfeeding activities (movements) of a single insect may initiate a response (17). Furthermore, the production of some plant defensive compounds such as certain terpenoid volatiles and methyl salicylate respond in a nonlinear manner to damage level (30).

Insect feeding and mechanical wounding can induce the same defensive pathways of a plant but the plant response levels and gene transcript profiles may differ $(6,32,40)$. In the present study, however, both exposure to fungus gnat larvae and mechanical damage $24 \mathrm{~h}$ prior to Pythium inoculation resulted in significant reductions in seedling mortality. Explanation for the lack of a significant relationship between plant wounding and Pythium infection when mechanical damage was inflicted immediately prior to inoculation may relate to the fact that zoospores are ephemeral, typically encysting and germinating within an hour of locating a host (14). Despite rapid plant defense reactions after herbivore contact, other studies with Nicotiana sylvestris reveal that systemic jasmonic acid responses do not reach a maximum until $180 \mathrm{~min}$ after wounding (3). In the present study, when wounding was done immediately prior to zoospore inoculation, there may not have been sufficient time for the geranium seedlings to mount a strong defensive response before becoming infected. Considering that fungus gnat larvae are almost always present in the greenhouse setting, plant defense reactions may occur frequently in response to wounding and insect feeding. Plants must regulate these responses, however, to balance defense and fitness costs.

An additional goal of this study was to investigate potential inhibitory characteristics of the fungus gnat-associated microbial community on $P$. aphanidermatum infection. Microorganisms may play important roles in interactions between macroorganisms and between macroorganisms and their pathogens. For example, microorganisms regurgitated by herbivores have been implicated in the induction of plant defense responses $(4,7,38)$. Also, nonpathogenic rhizobacteria have been shown to induce systemic resistance in plants similar to pathogen-induced systemic acquired resistance. Rhizobacteria-induced systemic resistance has been shown with fungi, bacteria, and viruses on various plants (4). Although microorganisms living in the soil may positively or negatively impact interactions among Pythium spp., fungus gnats, and geranium plants, there was no significant impact of the fungus gnats' external microbial community on subsequent $P$. aphanidermatum infection of geranium seedlings in this study.

Our investigations of fungus gnat-Pythium-geranium seedling interactions cannot be considered exhaustive. For example, we did not investigate potential inhibitory effects of microbes extracted from the guts of fungus gnats on $P$. aphanidermatum susceptibility. There is also the possibility of fungus gnat larvae directly interacting with plant pathogens and impacting their ability to infect plants. For example, salivary secretions from the fungus gnat, Bradysia coprophila, have been shown to inhibit germination of sclerotia from the plant pathogen Sclerotinia sclerotiorum (2). Also, larvae of the fungus gnat $B$. impatiens that ingested oospores and mycelium of $P$. aphanidermatum and then fed on cucumber roots growing in rockwool apparently introduced the pathogen to these plants (21). 
Although our studies demonstrate that previous exposure of geranium seedlings to fungus gnat larvae can result in reduced levels of Pythium infection, the development of new management strategies for fungus gnats is not warranted. Direct root feeding damage by fungus gnat larvae and transmission of plant-pathogenic conidial fungi by adult fungus gnats is well documented; thus, these insects should still be considered pests in most contexts $(12,19,23)$. Furthermore, the mechanisms of the observed interaction may be complex, with various additional factors affecting expression in commercial crop production systems, and investigation of these mechanisms is warranted. Overall, the findings of this study enhance our understanding of the association between fungus gnats and Pythium in greenhouse floriculture and indicate that ecological studies are needed to thoroughly explore soil pathosystems.

\section{ACKNOWLEDGMENTS}

This research was funded in part through a Specific Cooperative Agreement between the United States Department of AgricultureAgricultural Research Service (USDA-ARS) Plant Protection Research Unit and the Cornell University Department of Entomology, Ithaca, NY (Specific Cooperative Agreement 58-1907-4-447) funded by the USDAARS, as part of the Floriculture and Nursery Research Initiative. We thank M. Ramos and K. C. Bennett for technical support and L. Castrillo, A. Jack, and M. Ramos for providing useful comments on the manuscript.

\section{LITERATURE CITED}

1. Abbott, W. S. 1925. A method of computing the effectiveness of an insecticide. J. Econ. Entomol. 18:265-267.

2. Anas, O., Alli, I., and Reeleder, R. D. 1989. Inhibition of germination of sclerotia of Sclerotinia sclerotiorum by salivary gland secretions of $B$. coprophila. Soil Biol. Biochem. 21:47-52.

3. Baldwin, I. T., Zhang, Z., Diab, N., Ohnmeiss, T. E., McCloud, E. S., Lynds, G. Y., and Schmelz, E. A. 1997. Quantification, correlations and manipulations of wound-induced changes in jasmonic acid and nicotine in Nicotiana sylvestris. Planta 201:397-404.

4. Barbosa, P., Krischik, V. A., and Jones, C. G. 1991. Microbial Mediation of Plant-Herbivore Interactions. John Wiley \& Sons, New York.

5. Bruce, J. A., and Pickett, J. A. 2007. Plant defense signaling induced by biotic attacks. Curr. Opin. Plant Biol. 10:387-392.

6. Constabel, C. P., Yip, L., Patton, J. J., and Christopher, M. E. 2000. Polyphenol oxidase from hybrid poplar. Cloning and expression in response to wounding and herbivory. Plant Physiol. 124:285-295.

7. Dicke, M., and Hilker, M. 2003. Induced plant defenses: From molecular biology to evolutionary ecology. Basic Appl. Ecol. 4:3-14.

8. El-Hamalawi, Z. A. and Stanghellini, M. E. 2005. Disease development on Lisianthus following aerial transmission of Fusarium avenaceum by adult shore flies, fungus gnats, and moth flies. Plant Dis. 89:619-623.

9. Elmer, W. H. 2008. Preventing spread of Fusarium wilt of Hiemalis begonias in the greenhouse. Crop Prot. 27:1078-1083.

10. Finney, D. J. 1971. Probit Analysis, Third ed. Cambridge University Press, London.

11. Gardiner, R. B., Jarvis, W. R., and Shipp, J. L. 1990. Ingestion of Pythium spp. by larvae of the fungus gnat Bradysia impatiens (Diptera: Sciaridae). Ann. Appl. Biol. 116:205-212.

12. Gillespie, D. R. and Menzies, J. G. 1993. Fungus gnats vector Fusarium oxysporum f. sp. radicis-lycopersici. Ann. Appl. Biol. 123:539-544.

13. Glazebrook, J. 2005. Contrasting mechanisms of defense against biotrophic and necrotrophic pathogens. Annu. Rev. Phytopathol. 43:205-227.

14. Gow, N. A. R., Campbell, T. A., Morris, B. M., Osborne, M. C., Reid, B., Shepherd, S. J., and Van West, P. 1999. Signals and interactions between phytopathogenic zoospores and plant roots. Pages 285-305 in: Microbial Signaling and Communication (Society for General Microbiology Symposium No. 57). R. England, G. Hobbs, N. Bainton, and D. McL. Roberts, eds. Cambridge University Press, New York.

15. Graham, C. L., and McNeill, M. J. 1972. Soybean crown and root damage by Bradysia coprophila. J. Econ. Entomol. 65:597-599.

16. Green, T. R. and Ryan, C. A. 1972. Wound-induced proteinase inhibitor in plant leaves: A possible defense mechanism against insects. Science 175:776-777.

17. Hall, D. E., Kennaway, B. M., Nijsse, J., and Bown, A. W. 2004. Footsteps from insect larvae damage leaf surfaces and initiate rapid responses. Eur. J. Plant Pathol. 110:441-447.

18. Harris, M. A. 1995. Dissemination of the phytopathogen Thielaviopsis basicola by the fungus gnat Bradysia coprophila and biological control of these pests by Fusarium proliferatum and steinernematid nematodes. Doctoral dissertation, University of Georgia, Athens.

19. Harris, M. A., Gardner, W. A., and Oetting, R. D. 1996. A review of the scientific literature on fungus gnats (Diptera: Sciaridae) in the genus Bradysia. J. Entomol. Sci. 31:252-271.

20. Hatcher, P. E., Moore, J., Taylor, J. E., Tinney, G. W., and Paul, N. D. 2004. Phytohormones and plant-herbivore-pathogen interactions: Integrating the molecular with the ecological. Ecology 85:59-69.

21. Jarvis, W. R., Shipp, J. L., and Gardiner, R. B. 1993. Transmission of Pythium aphanidermatum to greenhouse cucumber by the fungus gnat Bradysia impatiens (Diptera: Sciaridae). Ann. Appl. Biol. 122:23-29.

22. Jarvis, W. R., and Shoemaker, R. A. 1978. Taxonomic status of Fusarium oxysporum causing foot and root rot of tomato. Phytopathology 68:16791680.

23. Kalb, D. W., and Millar, R. L. 1986. Dispersal of Verticillium albo-atrum by the fungus gnat (Bradysia impatiens). Plant Dis. 70:752-753.

24. Kaplan, I., Halitschke, R., Kessler, A., Sardanelli, S., and Denno, R. F. 2008. Constitutive and induced defenses to herbivory in above- and belowground plant tissues. Ecology 89:392-406.

25. Leath, K. T. and Newton, R. C. 1969. Interaction of a fungus gnat, Bradysia sp. (Sciaridae) with Fusarium spp. on alfalfa and red clover. Phytopathology 59:257-258.

26. LeOra Software. 2002. Polo-Plus Probit and Logit Analysis User's Guide. LeOra Software Inc., Berkeley, CA.

27. Mansouri, H., Paige, R. L., and Surles, J. G. 2004. Aligned rank transform techniques for analysis of variance and multiple comparisons. Commun. Stat. Theory 33:2217-2232.

28. Mayer, R. T., Inbar, M., McKenzie, C. L., Shatters, R., Borowicz, V., Albrecht, U., Powell, C. A., and Doostdar, H. 2002. Multitrophic interactions of the silverleaf whitefly, host plants, competing herbivores, and phytopathogens. Arch. Insect Biochem. Physiol. 51:151-169.

29. McConn, M., Creelman, R. A., Bell, E., Mullet, J. E., and Browse, J. 1997. Jasmonate is essential for insect defense in Arabidopsis. Proc. Natl. Acad. Sci. USA 94:5473-5477.

30. Mithöfer, A., Wanner, G., and Boland, W. 2005. Effects of feeding Spodoptera littoralis on lima bean leaves. II. Continuous mechanical wounding resembling insect feeding is sufficient to elicit herbivoryrelated volatile emission. Plant Physiol. 137:1160-1168.

31. Okubara, P. A., and Paulitz, T. C. 2005. Root defense responses to fungal pathogens: A molecular perspective. Plant Soil 274:215-226.

32. Reymond, P., Weber, H., Damond, M., and Farmer, E. E. 2000. Differential gene expression in response to mechanical wounding and insect feeding in Arabidopsis. Plant Cell 12:707-719.

33. Richter, S. J., and Payton, M. E. 1999. Nearly exact tests in factorial experiments using the aligned rank transform. J. Appl. Stat. 26:203-217.

34. Robertson, J. L., Russell, R. M., Preisler, H. K., and Savin, N. E. 2007. Biossays with Arthropods, Second ed. CRC Press, Boca Raton, FL.

35. Rostas, M., Simon, M., and Hilker, M. 2003. Ecological cross-effects of induced plant responses towards herbivores and phytopathogenic fungi. Basic Appl. Ecol. 4:43-62.

36. SAS Institute. 2002. JMP Statistics and Graphics Guide: Version 4. SAS Institute Inc., Cary, NC.

37. Sokal, R. R., and Rohlf, F. J. 1995. Biometry: The Principles and Practice of Statistics in Biological Research, Third ed. Freeman, New York.

38. Spiteller, D., Dettner, K., and Boland, W. 2000. Gut bacteria may be involved in interactions between plants, herbivores and their predators: microbial biosynthesis of $\mathrm{N}$-acylglutamine surfactants as elicitors of plant volatiles. Biol. Chem. 381:755-762.

39. Waite, M. B. 1891. Results from recent investigations in pear blight. Bot. Gaz. 16:259

40. Zong, N., and Wang, C. 2007. Larval feeding induced defensive responses in tobacco: Comparison of two sibling species of Helicoverpa with different diet breadths. Planta 226:215-224. 